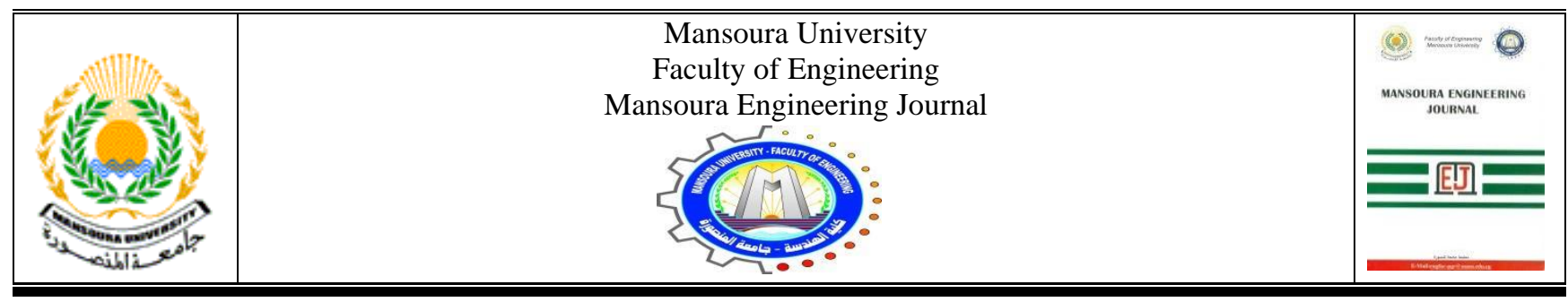

\title{
Towards a framework for studying visual attention indicators in a street design environment using an eye tracking device
}

\author{
Mehad Sayed Ebrahim Hassan Emara
}

\author{
KEYWORDS: \\ Attention-visual \\ attention - eye tracking \\ system - different street \\ types
}

\begin{abstract}
Streets are the most flexible elements in the city where its boundaries are drawn by the boundaries of buildings and properties, and the primary means of planning new streets and the surrounding environment surrounding them is to develop a two-dimensional plan, but this plan is criticized at times because of its inability to take the 3D world in Consideration and consequently their inability to predict the actual outcome of the plan, And to address this criticism, this paper explores empirically whether visual distributions can be predicted through a two-dimensional plan. Experiments and research were conducted in Sweden on a set of images through the eye tracking system, and human visual attention was measured to street types: ( Blocked, open, curved, angle), The results show that different types of visual attention are evoked by each of the four different street types.

Consequently, the research aims to study the two-dimensional plans that are studied through the eye tracking system, and to study its ability to predict future three-dimensional results of a particular plan in terms of visual attention, and then move to the research methodology and through it will come out with a set of indicators through studying previous experiences To use the eye tracking system, these indicators are valuable for planners, architects and decision makers when planning new urban environments through the importance of understanding the human perception of streets in a broader context.
\end{abstract}

اتخاذ القرار ات المتعلقة بأنماط النمو من خطة استخدام الأر اضي ثنائية الأبعاد،

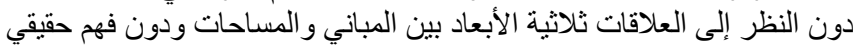

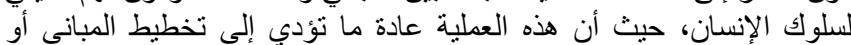

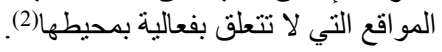

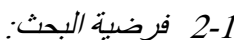
من المكن التنبؤ بالاهتمام البصري البشري فئري في بيئة الشوارع الحضرية

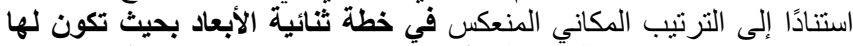

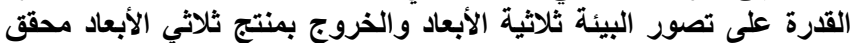

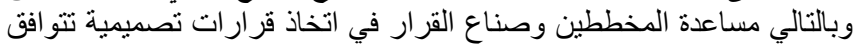
مع الو القع.

$$
\text { 3-1 3 العدف من البحث: }
$$

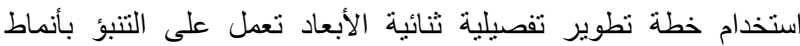

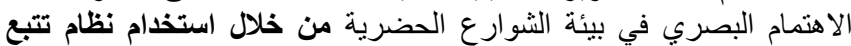

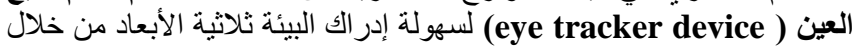

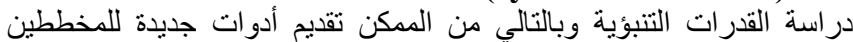
وصناع القرار في سعيهم لخلق بيئة مبنية تتو افق مع التهدف لفئ المنشود. 4-1 - 4 - الأسئلة البحثية:

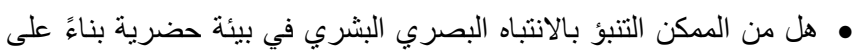

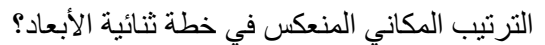

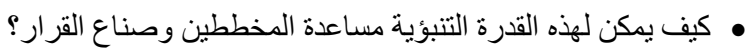

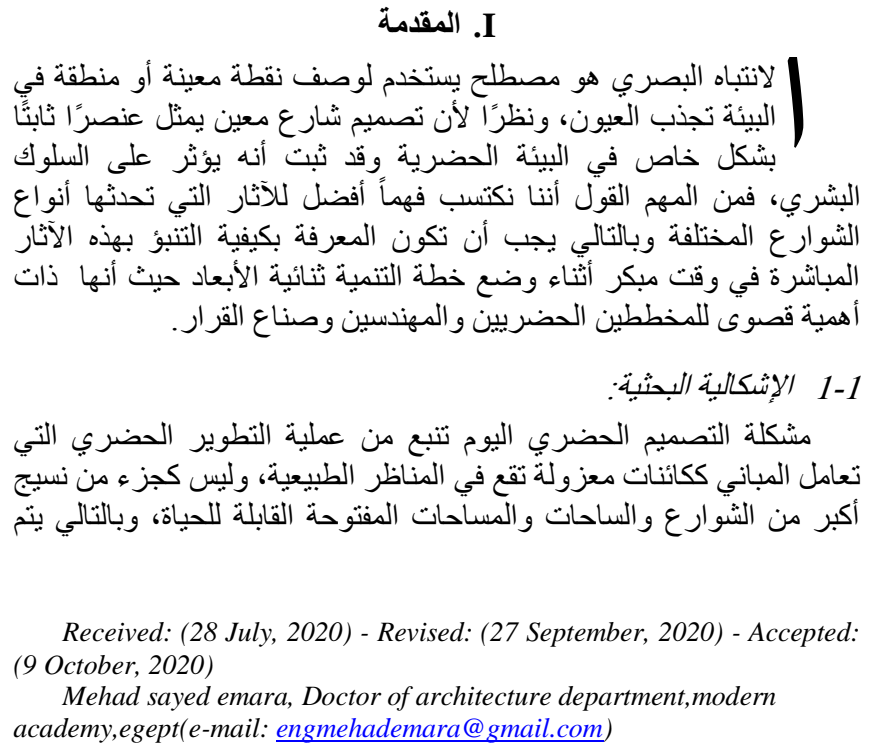


3-2 ملامح الثوارع و عناصر ها:

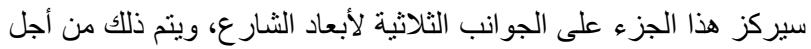

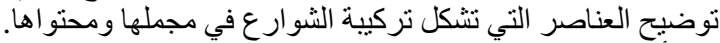

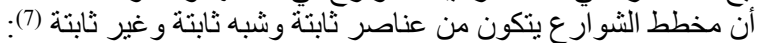

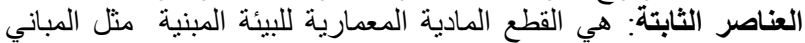

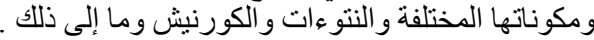

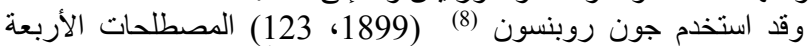

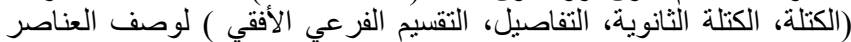

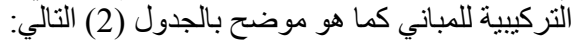

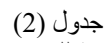

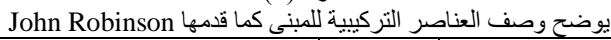

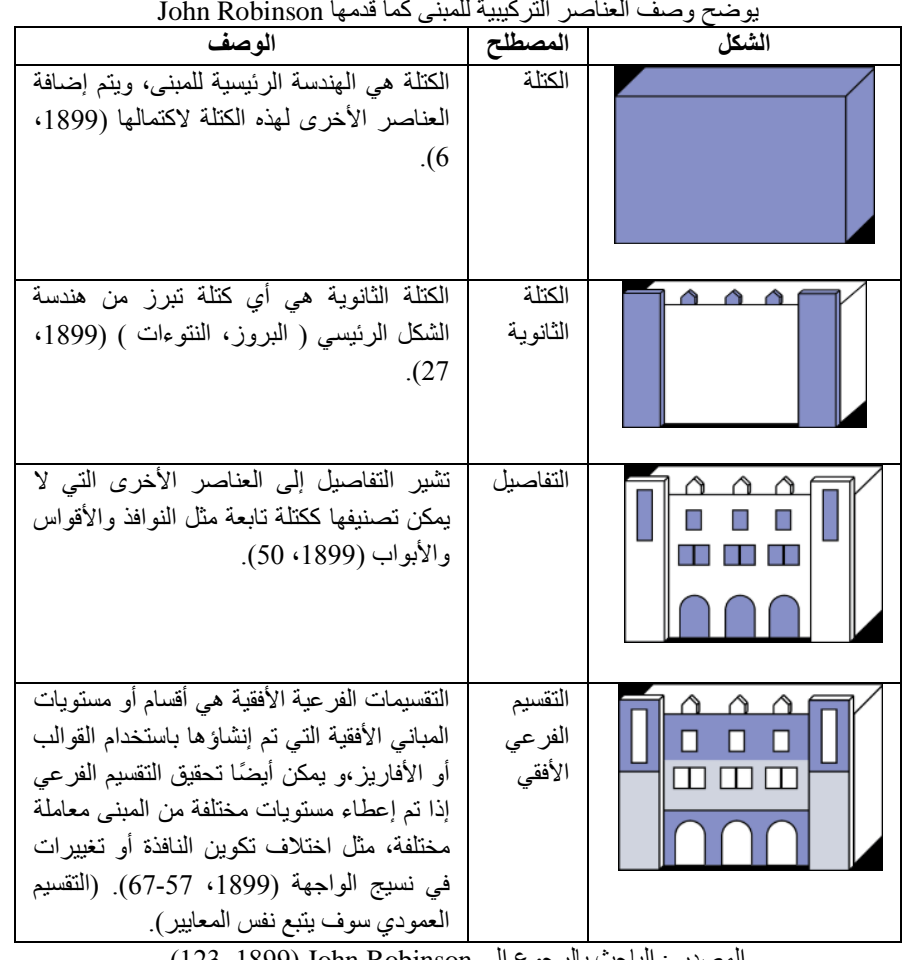

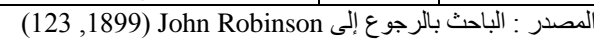

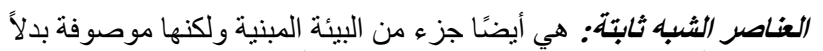

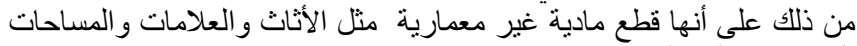

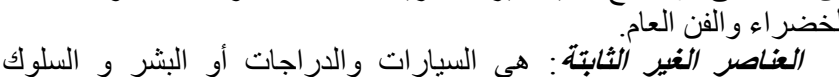

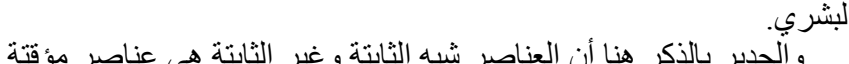

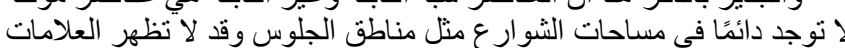

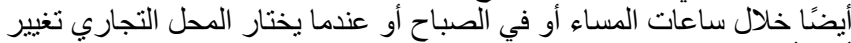

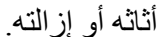

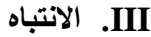

تقوم موسوعة علم النفس بتعريف الانتباه على أنه ذلك النشاط الانتقائي

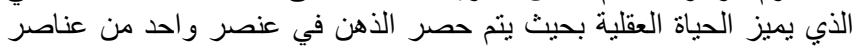

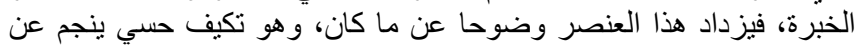

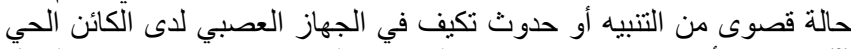
(9). ويمكن أن نحدد الانتباه حسب التعريف السابق كما هو موضح لإن بالشكل

التالي (2): (1)

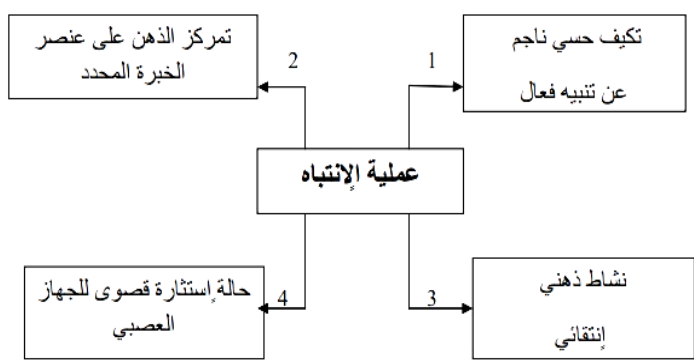

شكل (2) يوضح الضبط المفاهيمي لعملية الانتباه حسب ( موسو عة علم النفس) المصدر : موسو عة علم النفس لمسر
5-1 منهجية البحث:

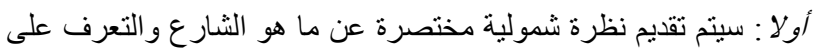

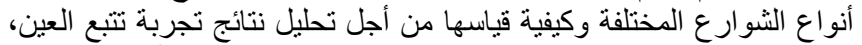

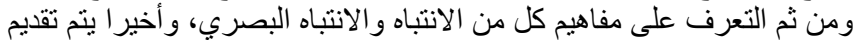

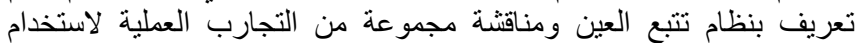

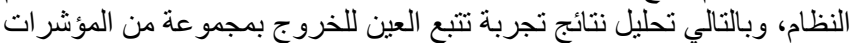

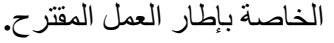

\section{c. الثوارع في المدن وأنواعها}

1-2 تعريف الثارع:

يمكن تعريف الثارع بانه الجزء المعارع المعبر عن محتوى الوجود الانساني

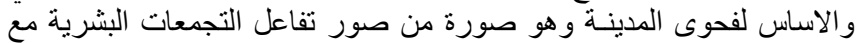

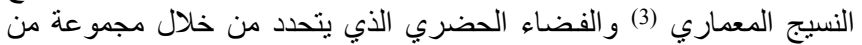

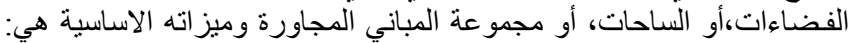

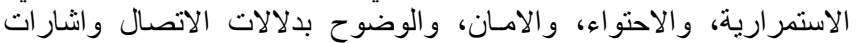

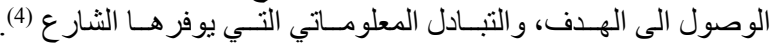

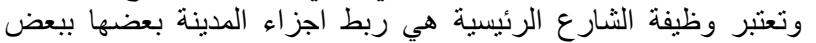
وتمثنل ممـر ات لحركة الاشخاص و وانتقالهم وكذللك مسالك للسيار ات وات والبضائع

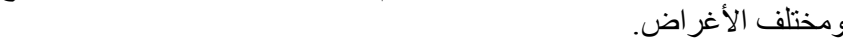

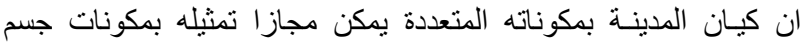

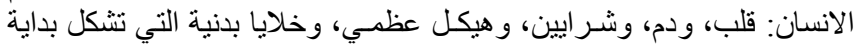

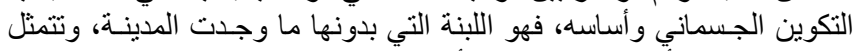

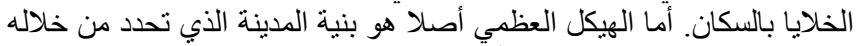

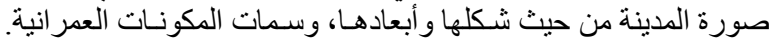

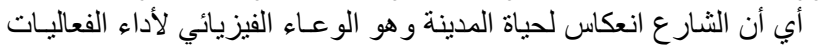

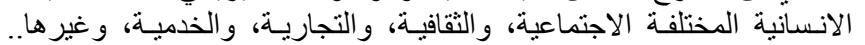

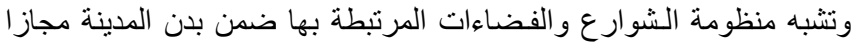

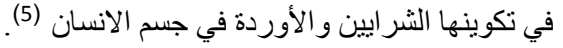
2-2 انواع الثوارع:

الثوارع تصنف عادة من حيث الثكل إلى: شو ارع ارع مستقيمة، أو منحنيـة،

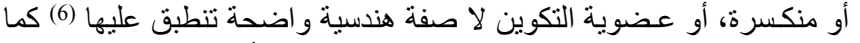

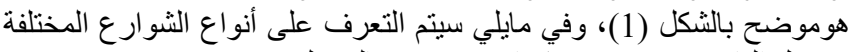
من قبل الباحث Marshall كما هو موضي سئح بالجدول (1)،

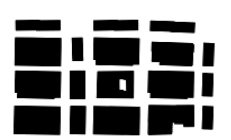

Grid

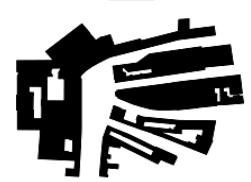

Radial concentric

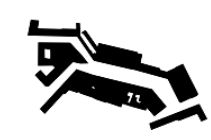

Angular

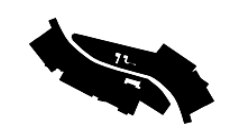

Curvilinear

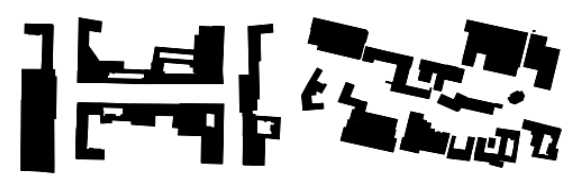

Axial

Organic

شكل (1) يوضح مختلف العلاقات بين ( الفارغ - الصلب) لأنو اع الثوارع المختلفة مع نوضيح

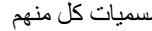

المصدر: Marshall (2006, 75 (15)

(1) جدول

Marshall وضح أشكال الثوارع / المستوطنات كما قدمها (1)

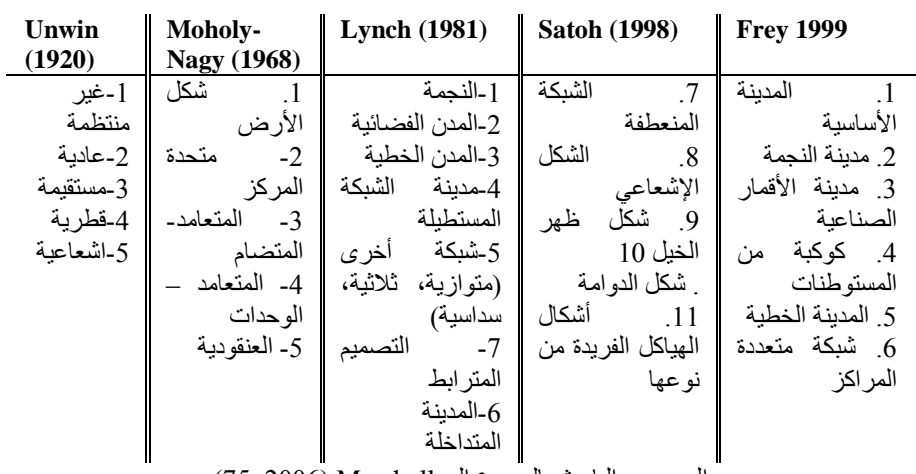

المصدر : الباحث بالرجوع إلى Marshall (2006, 75) 
أرفف السوبرماركت أو الجسم الذي نود أخذ معلومات أكثر عن كيفية النظر

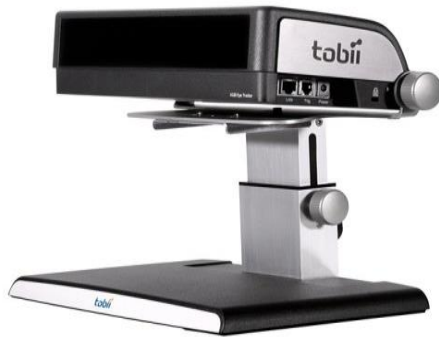

شكل (4) يوضح جهاز تتبع حركة العبن

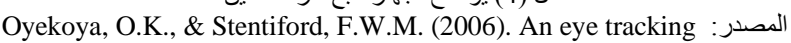
interface for image search. Proceedings of the 2006 Symposium on Eye

Tracking Research \& Applications, p. 40. New York: ACM Press

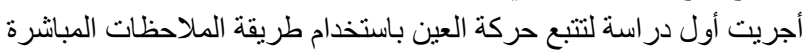

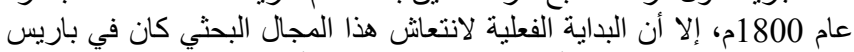

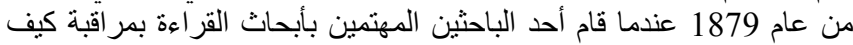

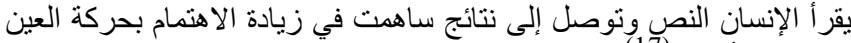
بعدها في القرن التاسع عشر بدأت تظهر بعض التهان الأجهزة البدائية لتقنين

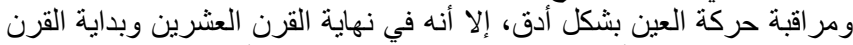

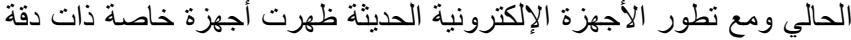
عالية تعطي قر اءات منضبطة لتتبع حركة العين في السويد.

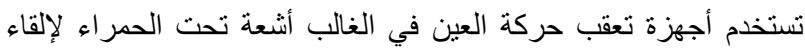

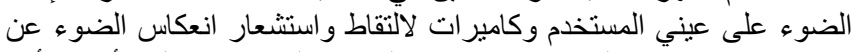

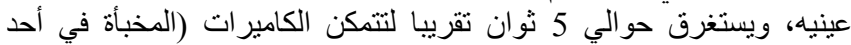

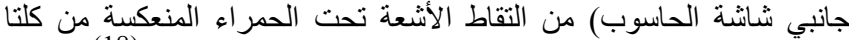

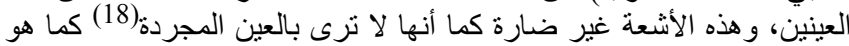
وتساعد هذه الطريقة في نتبع مسار العين على الجسم الذي يتم النظر إليه

وجمع معلومات أخرى منل وقت النظر واتجاهله وحدة التركيز ولتئ وغير ها.

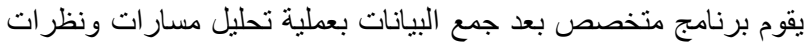

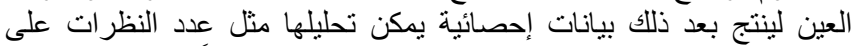

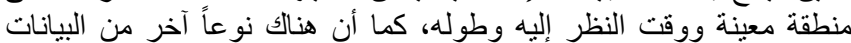

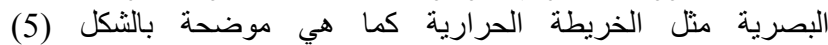

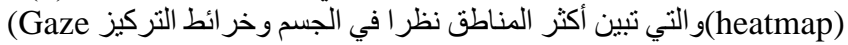

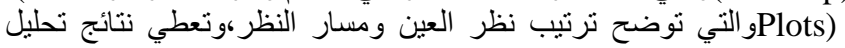

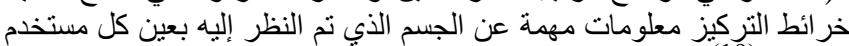

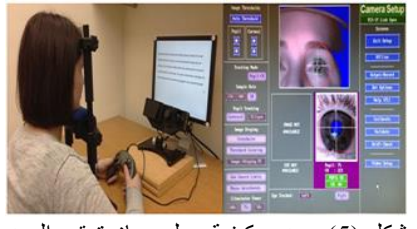

شكل (5) يوضح كيفية عمل جهاز تعقب العين من خلال تحليل تتبع العين تركز على على خرائط الحرارة المنتجة

Martin Månsson (2017). Patterns and predictability of visual attention in different street type,

Master's Thesis in Spatial Planning, $30 \mathrm{hp}$ Blekinge Institute of Technology شكل (5) يوضح كيفية عمل جهاز تعقب العين من خلال تحليل تتبع العين تركز على خر ائط

Martin Månsson (2017). Patterns and predictability of visual attention in different street type, Master's Thesis in Spatial Planning, $30 \mathrm{hp}$ Blekinge Institute of Technology Martin Månsson (2017). Patterns and predictability of visual attention in different street type, Master's Thesis in Spatial Planning, $30 \mathrm{hp}$ Blekinge Planning, $30 \mathrm{hp}$
إليه كما هو موضح بالثكل (4).

$$
\text { 1-4 تاريخ تتبع حركة العبن في الأبحاث: }
$$
كمصدر للأبحاث الإن (17).

4-4 كيفية عمل أجهزة تتبع العين: موضح بالثكل (6) الأندة.

3-4 نتائج تعقب حركة العبين:

على حدة:19)

3-1 الانتباه البصري:

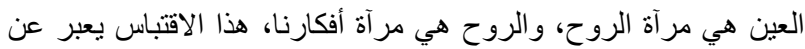

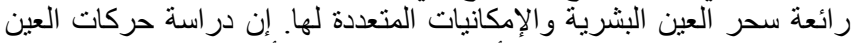

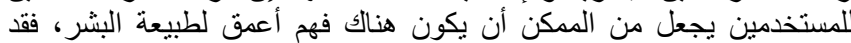

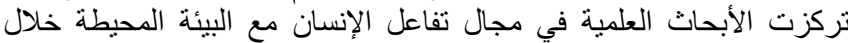

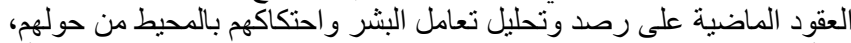

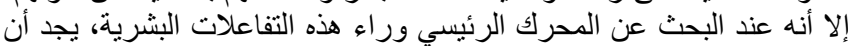

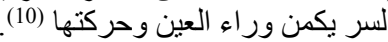

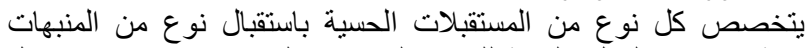

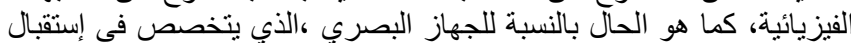

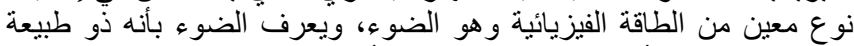

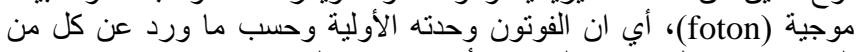
الباحين في مجال الانتباه البصري(أتكنسون و هيلجارد) Atkinson RL et)

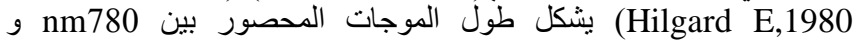
nm380

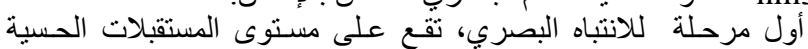

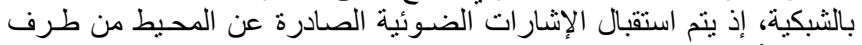

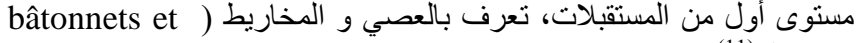
(11) (cones • العصي: مخصصة لإستقبال المنبهات الضـوئية ذات الثّدة الضعيـفة والتي وإني

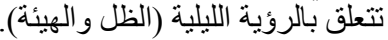

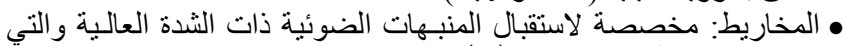
تتعلق برؤية الألوان النهارية (12).

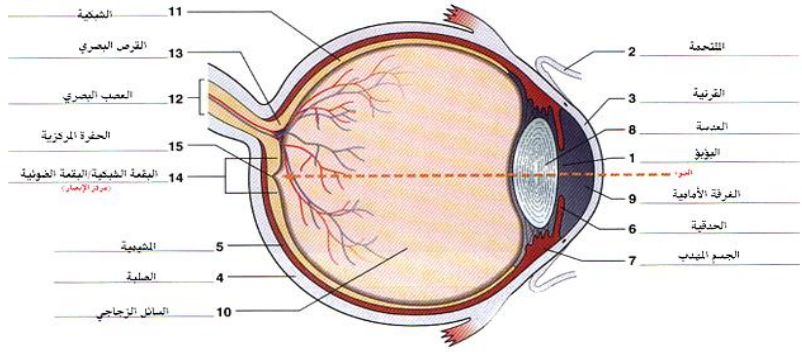

شكل (3) يوضح شرح بسيط لأعمال العين ذات الصلة في سياق در اسة تثتع العين. https://www.mayoclinic.org/ar/diseases-conditions/retinal- المصني diseases/symptoms-causes/syc-20355825

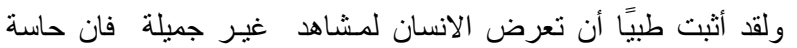

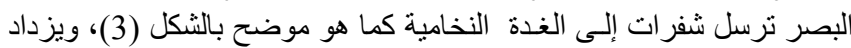

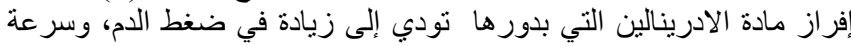

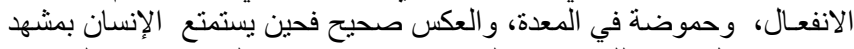

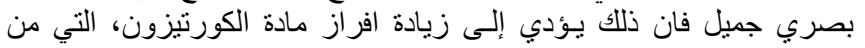

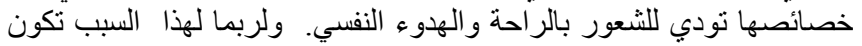

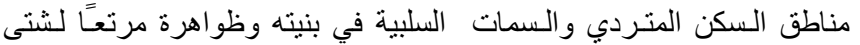

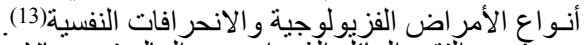

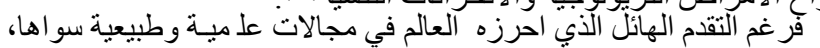

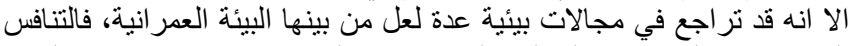

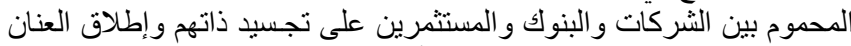

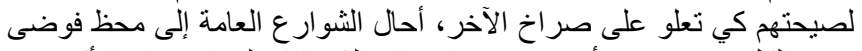

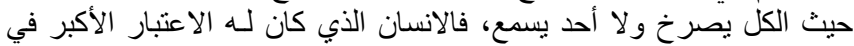

تر اكيب مدن الأمس، أضـدل اليوم مقياستا وانتماء إلى بنيته الحضرية.

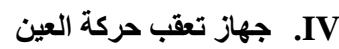

يقوم جهاز تعقب العين بقياس وظائف العين وحركتها لتحديد نقاط التركيز

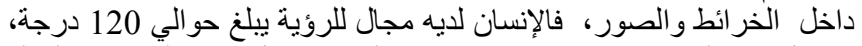

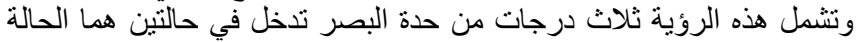

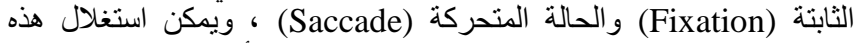

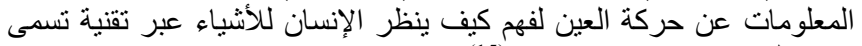

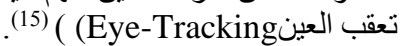
ويستخدم جهاز تعقب حركة العين في عدد من المجالات البحثية المختلفة

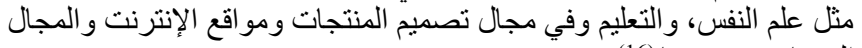
المعماري و غير ها لالفئ (16) كما نتنوع الأجهزة المستخدمة في تعقب حركة أنس العين وتختلف في تعقيدها

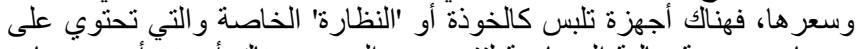

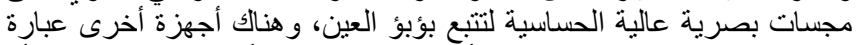

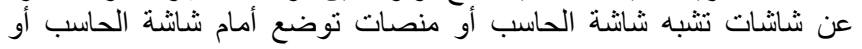




\begin{tabular}{|c|}
\hline $\begin{array}{c}\text { Amount of visual } \\
\text { attention }\end{array}$ \\
\hline Very high \\
\hline High \\
\hline Medium \\
\hline low \\
\hline none \\
\hline
\end{tabular}

شكل (9) نقطة الانتباه البصري.

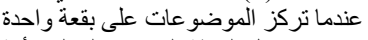
محددة، تحصل النقطة المحددة على لون أكثر دفيًا

Martin Månsson (2017): دفا

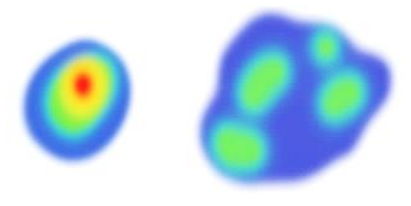

شكل ( 8) تركيز الانتباه البصري.

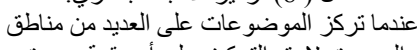

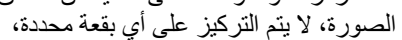

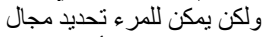

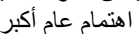

Månsson (2017) Martin : المصدر عامر

3-5 أدوات تحليل التجربية:

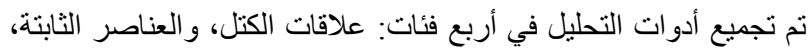

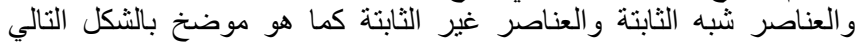
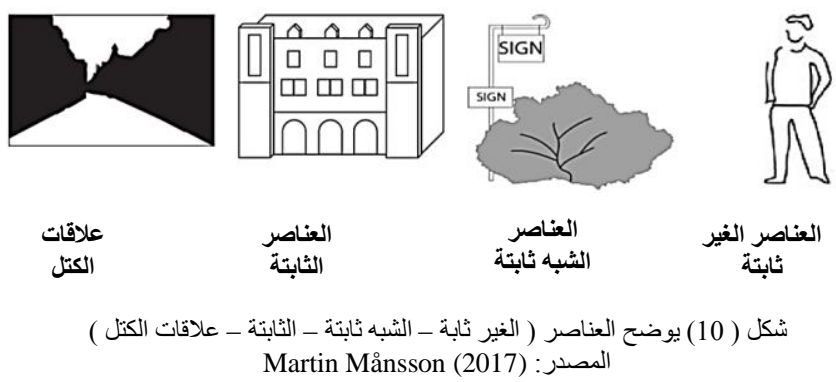

كل فئة من هذه الفئات الأربع تمتلك صفات يتتقد أنها تؤثر على الانتباه

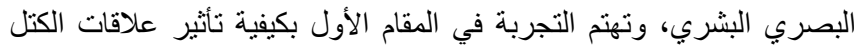

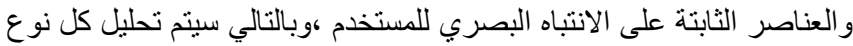

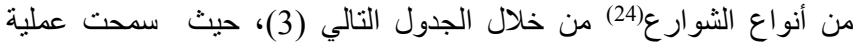

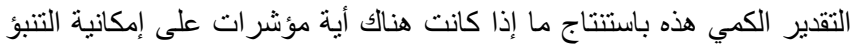

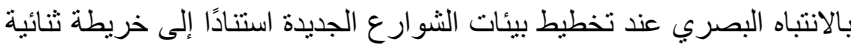

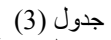

جدول يوضح تصميم الاستيبان لرصد آراء المستخدمين المختلفة

\begin{tabular}{|c|c|c|}
\hline \multicolumn{3}{|c|}{ عدد المحفزات، ونوع الثشارع، اسم الثارع، المدينة، البلد } \\
\hline الثكل نتيجة الصورة النهائي & الشكل نتيجة نقطة الانتباه & وجه المقارنة \\
\hline & & الثكل - l- الثل \\
\hline الوصف & الوصف & علاقات الكتل \\
\hline الوصف & الوصف & الغناصر الثَابتة \\
\hline الوصف & الوصف & العناصر الثبته \\
\hline الوصف & الوصف & الثناصيتة الغير \\
\hline
\end{tabular}

الهصدر : الباحث بالرجوع إلى Marshall (2006, 75)

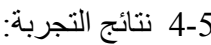

تم إجر اء الاختبار على مجمو عة من أنواع الثوار الثرع المختلفة (المستقيمة

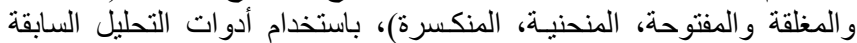

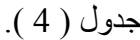

V تجارب علمية في مجال استخدام تقتية تتبع العين للشوارع الحضرية في السويد

$$
\text { 1-5 خطوات / إجراء التجربة: }
$$

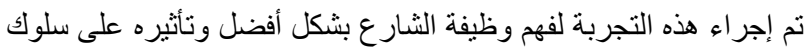

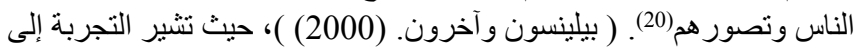

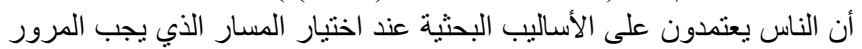

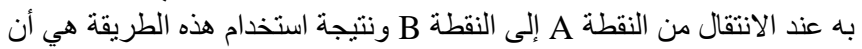

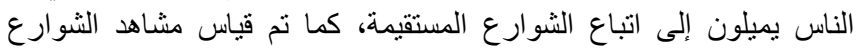

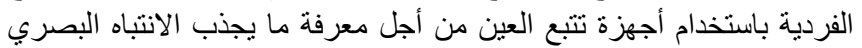
للبشر الذين يدركون مشهدًا معينًا.

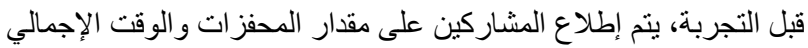

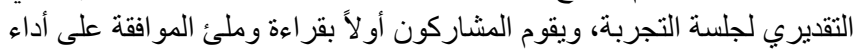

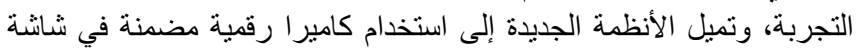

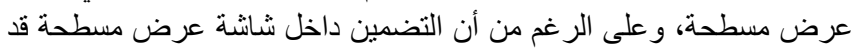

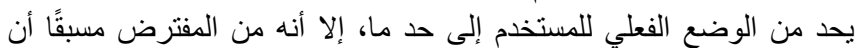

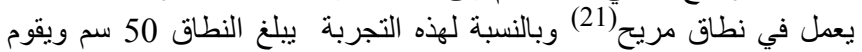

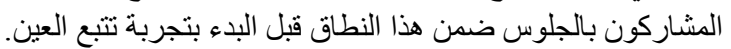

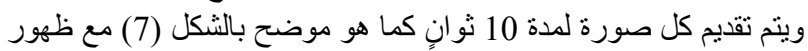

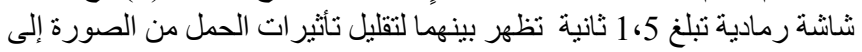

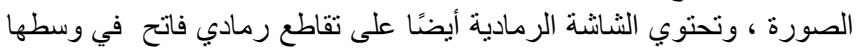

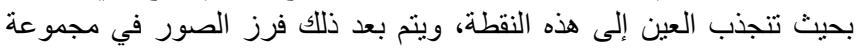

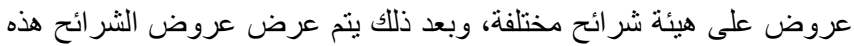

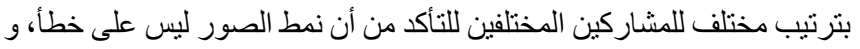

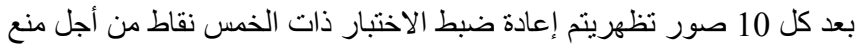

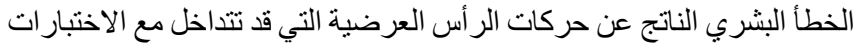
السابقة، وفي المجموع سيتم إجر اء أربعة اختبار ات الكل الكل مشارك الك.

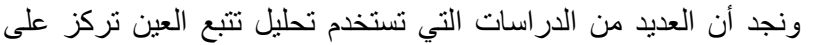

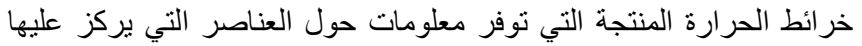

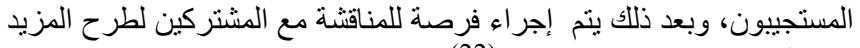

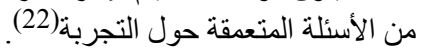

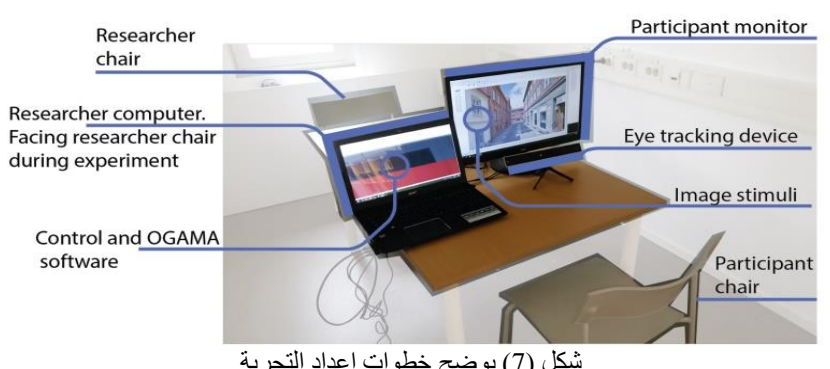

Oyekoya, O.K., \& Stentiford, F.W.M. (2006). An eye tracking المصدر interface for image search. Proceedings of the 2006 Symposium on Eye Tracking Research \& Applications, p. 40. New York: ACM Press

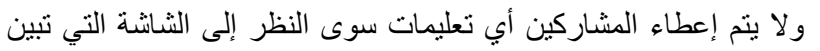

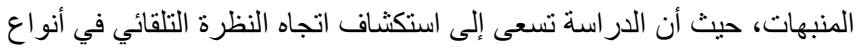

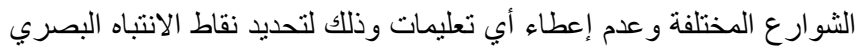
بشكل دقيق.

2-5 تحلبل التجربة:

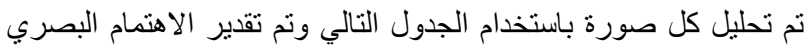

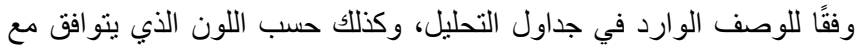

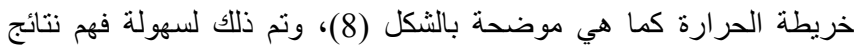

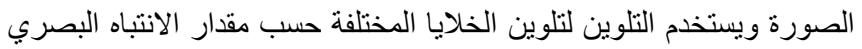

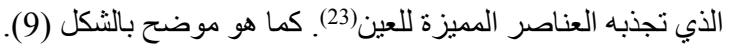




\begin{tabular}{|c|c|c|}
\hline 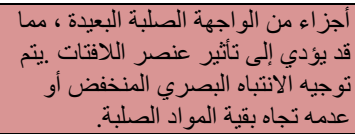 & المتنقية إلى المواد الصلبة المحيطة & \\
\hline 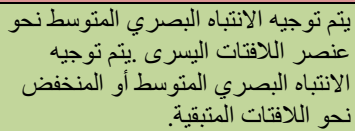 & & الثباصه ثابتة \\
\hline الدر توجات المتوفقة. الانتباه البري المنخفض إلى & & الغناصر ثابيتة \\
\hline
\end{tabular}

المصدر : الباحث بالرجوع إلى Marshall (2006, 75)

• - نموزج لشارع زو نهاية منكسرة:

جدول (7)

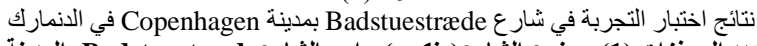

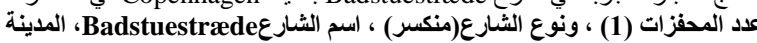
Denmark Copenhagen

\begin{tabular}{|c|c|c|}
\hline الشكل نتيجة الصورة النهائي & الثكل نتيجة نقطة الاتتباه & المقارنة \\
\hline & & الثكل \\
\hline 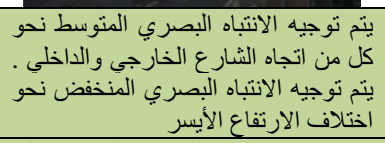 & 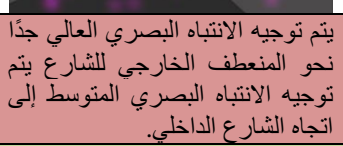 & الكتل علات \\
\hline 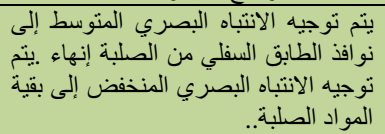 & 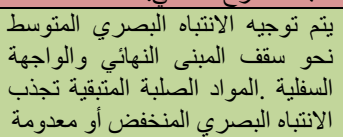 & الثناصر \\
\hline 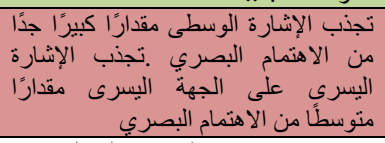 & & الثبه ثابتة \\
\hline لا يتم توجيه الانتباه البصري إلى الناس & & الغير ثابترة \\
\hline
\end{tabular}

المصدر : الباحث بالرجوع إلى Marshall (2006, 75)

ومن خلال عرض تحليل التجارب السابقة لأنواع مختلفة من الثوارع

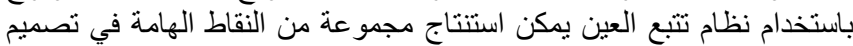

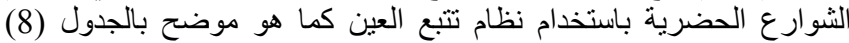

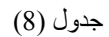

نتائج اختبار مجموعة من التجارب العالمبة باستخدام جهاز تعقب حركة العين

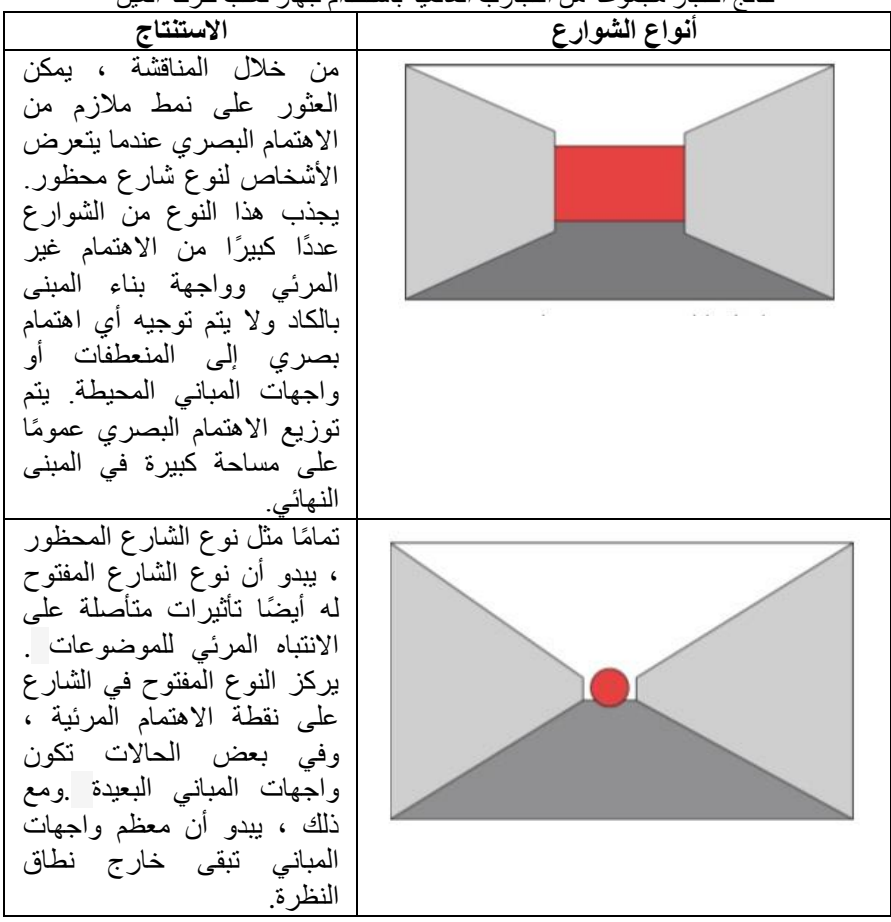

• نموذج لشارع ذو نهاية مغلقة: (غير منتظمة)

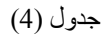

يوضح نتائج اختبار التجربة في شارع Horsstræde بمدينة Holsterbo في الدنمارك

عدد المحفزات (2)، ونوع الثارع (مظلق)، اسم الثارع Horsstræde، المدينة

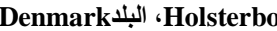

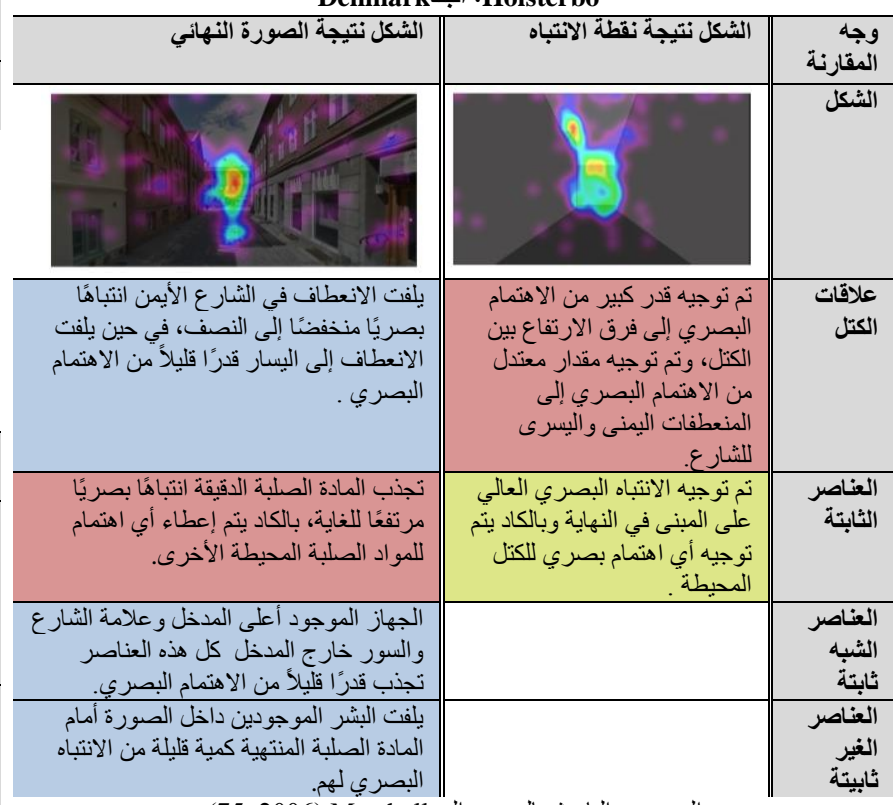

المصدر : الباحث بالرجوع إلى Marshall (2006, 75 $)$

\section{• نموذج لثارع نو نهاية مفتوحة: ( اشعاعية ، مستقيمة ، عادية)}

جدول (5)

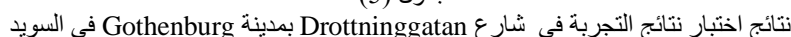
عدد المحفزات (1) ، ونوع الثشارع(مفتوح) ، اسم الثارعDrottninggatan؛ الثدينة Sweden Gothenburg

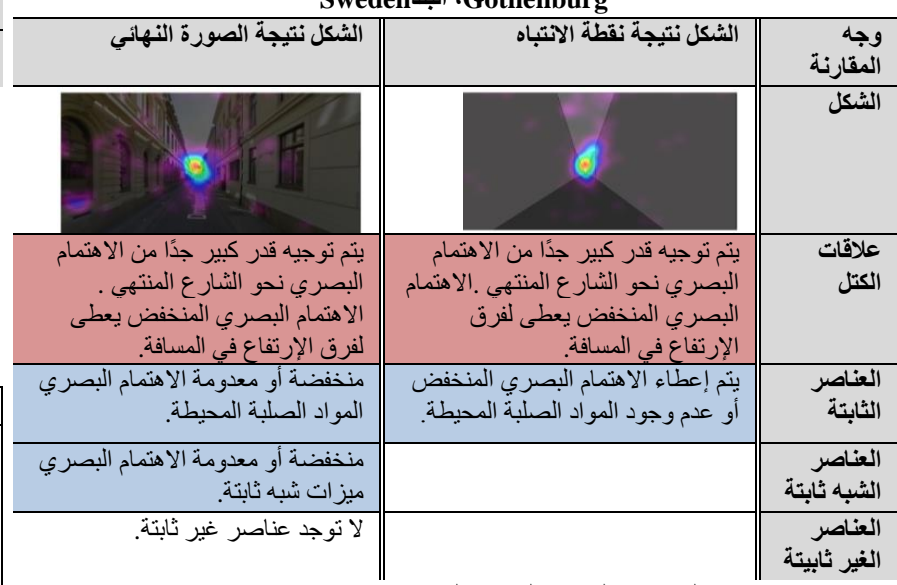

المصدر : الباحث بالرجوع إلى Marshall (2006, 75 (

\section{• نموذج لشارع ذو نهاية منحنية: (قطرية ، غير منتظمة ومنكسرة )}

جدول (6) (2)

نتائج اختبار التجربة في شارع Magstræde بمدينة Copenhagen في الدنمارك عدد المحفزات (2) ، ونوع الثنارع(منحني) ، اسم الثنارع) Magstræded المدينة Denmark Copenhagen

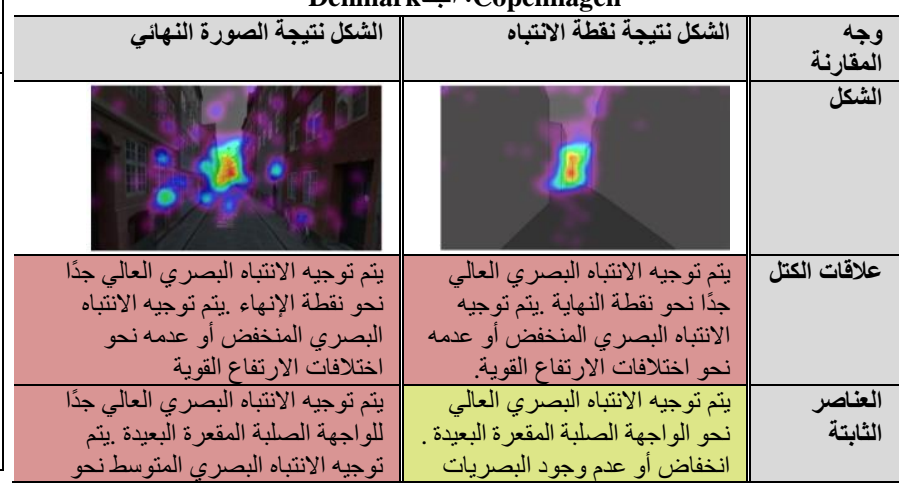




\begin{tabular}{|c|c|c|}
\hline 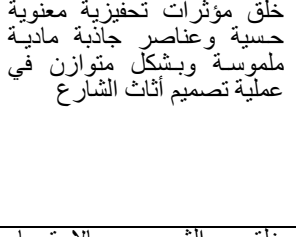 & 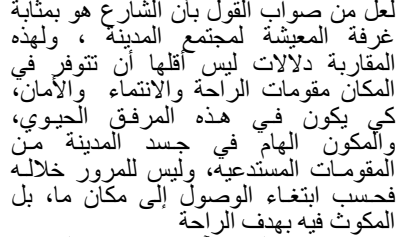 & $\stackrel{\widetilde{c}}{\underline{E}}$ \\
\hline والراحة البصرية بالاستجمام & 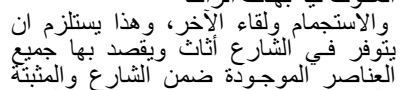 & E. \\
\hline خلق بيئة حيوية & 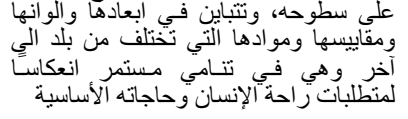 & \\
\hline
\end{tabular}

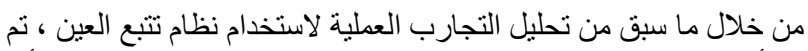

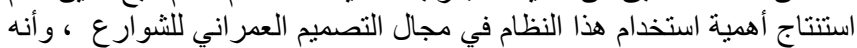

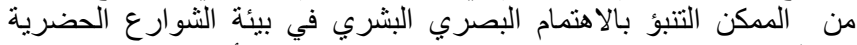

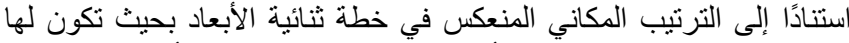

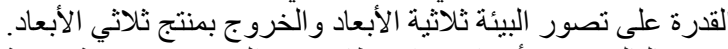

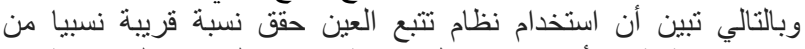

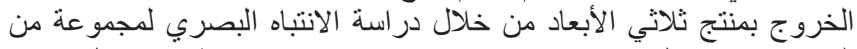

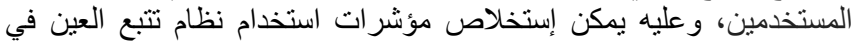

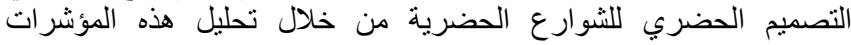
و إدر اجها للوصول إلى إطار العمل المقترح حسئ وكما يلي:

\section{.VI التصميم الحضري للثوارع التصنية الحضرية}

جدول (10)

يوضح إطار العمل المقترح لتقييم مؤشرات استخدام نظام تتبع العين في التصميم الحضري

\begin{tabular}{|c|c|}
\hline \multicolumn{2}{|c|}{ 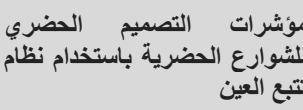 } \\
\hline \multicolumn{2}{|c|}{ داخل الثارع التوازن بين الكتل العمر انية } \\
\hline لتماعي & ج التفاعل 1 \\
\hline \multicolumn{2}{|c|}{ لتنقل سيراة المقياس الإنساني أثناء } \\
\hline المحيط & مل مع الإقلِ \\
\hline و الجمالية لفضاء & القيم الفن: \\
\hline عة المباني و & و وم \\
\hline الخطوط & 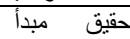 \\
\hline الأشكال & \\
\hline الأحجام & ووازن مسن \\
\hline الألوان & \\
\hline الملمس & \\
\hline مو اد ب الانهاء & \\
\hline المستخدمة & \\
\hline
\end{tabular}

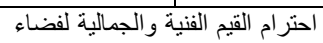

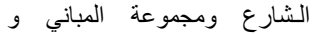

الساحات و الميادين الحضرية

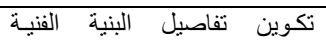
للطرق وروت واجهاتها و والميادين

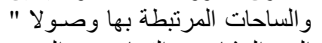

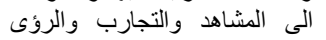

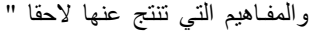
لدى المتلقي في ذاكرته

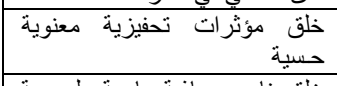
ولقئعناصر جاذبة ماديـة ملموسـة

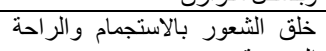
البصرية خلق بيئة حيوية البهة
للشو ار ع الحضرية آنضية

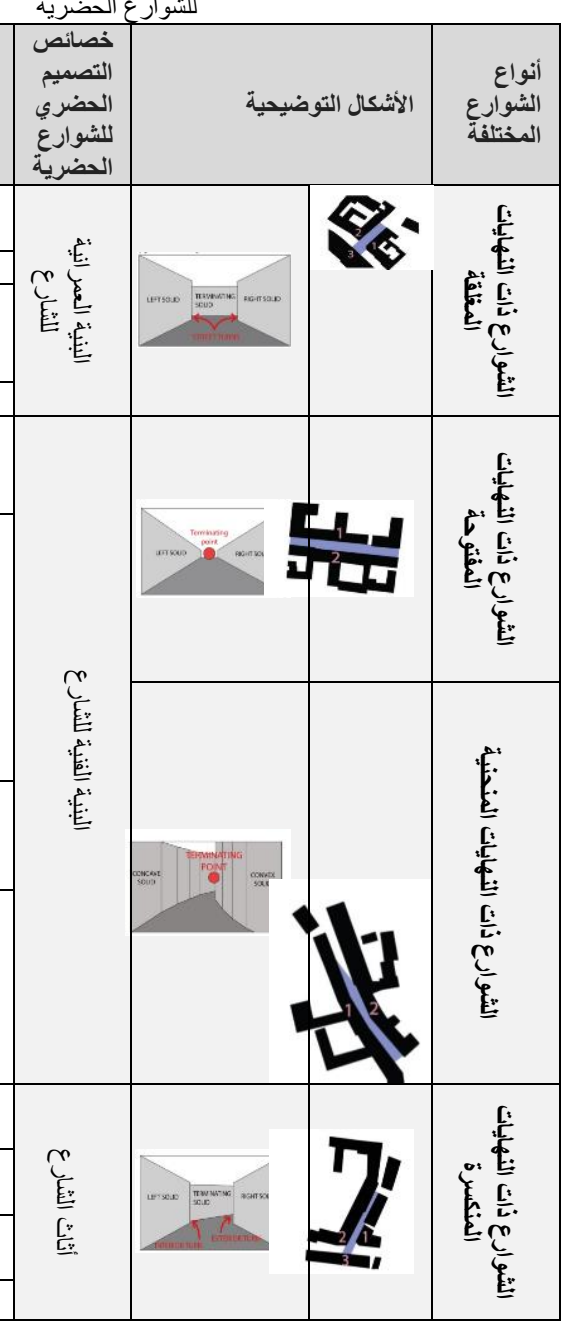

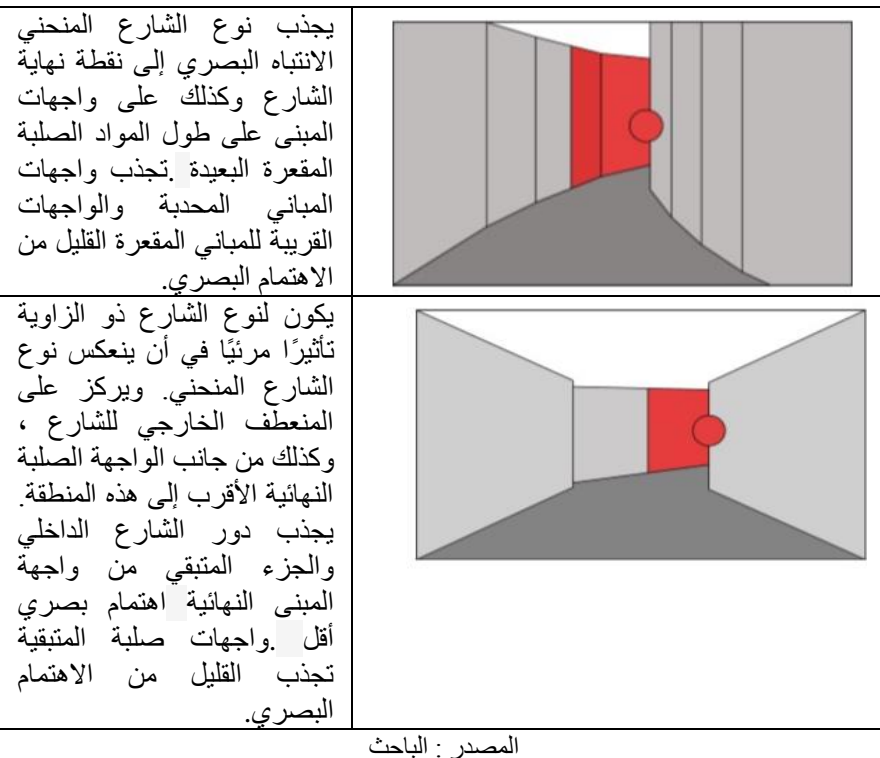

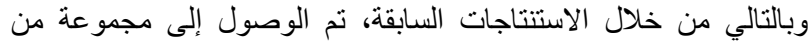

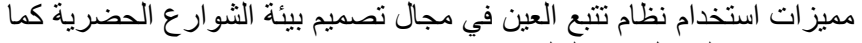
هو موضح بالجدول (9) التنالي.

5-5 معيز/ت /ستخدام نظام تتبع العبن في مجال التصميم العدراني للثشوارع: جدول (9)

يوضح الآثار السلبية وأسباب تفاقم مشكلة تصميم الثشو ارع الحضرية و الآثار الايجابية لاستخدام

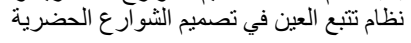

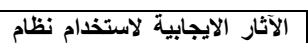

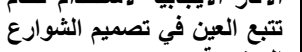

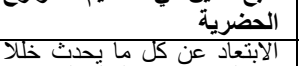
في التوازن بين الكتل العمرانية دافخل الثنارن عين

ترويج التفاعل الإجتماعي

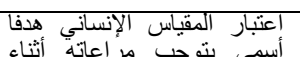

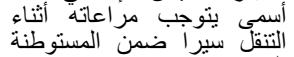
الو احدة سبرا ضمن المستوطنة

التكامل مع الإقليم المحيط

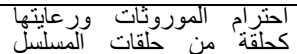
كحلقة من حلقات المسلسل

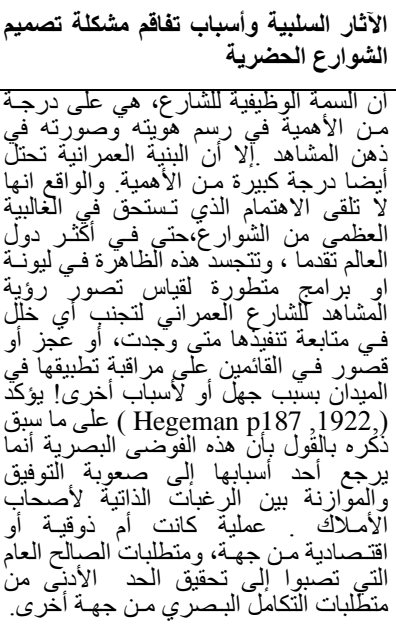

احترام القيم الفنية والجمالية

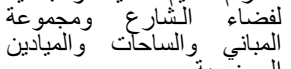

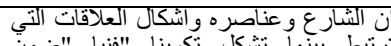

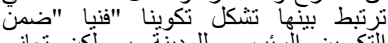

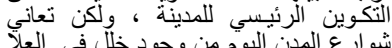

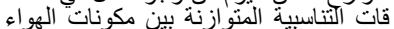

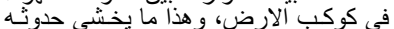

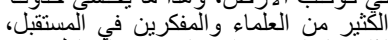

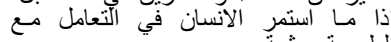

تحقيق مبدا الوحدة والتوازن من خـال خطوط، واشكال،

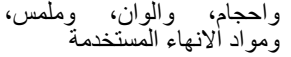

تكوين تفاصيل البنية الفنيـة للطرق وواجهاتها و والميادين

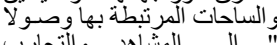

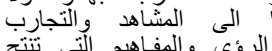

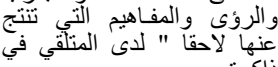

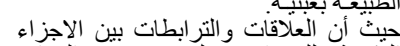

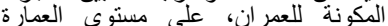

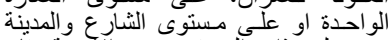

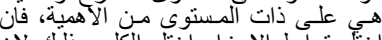

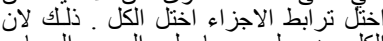

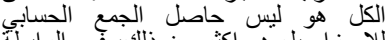
للاجزاء بل هو اكثر من ذلك، فهو الرابطة بين الاجز اء المكونة للكل، فالعين البشرية

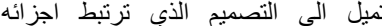

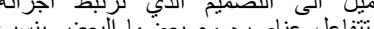

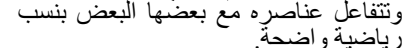


[13] Mahdjoubi, L., \& Wiltshire, J. (2001). Towards a framework for evaluation of computer visual simulations in environmental design. Design Studies.

[14] Sheppard, S. R. (2001). Guidance for crystal ball gazers: developing a code of ethics for landscape visualization. Landscape and urban planning.

[15] Duchowski, A. (2007). Eye tracking methodology: Theory and practice ( $2^{\text {nd }}$ ed.) Springer-Verlag, London.

[16] Jaewan Park1, Yan Jin1,2, Sihyeong Ahn1, Sangwon Lee1(2019), The Impact of Design Representation on Visual Perception: Comparing Eye-Tracking Data of Architectural Scenes Between Photography and Line Drawing

[17] Horsley, M., Eliot, M., Knight, B. A. \& Reilly, R. (2014). Current Trends in Eye Tracking Research Springer international Publishing.

[18] Granka, L., Joachims, T., \& Gay, G. (2004). Eye-tracking analysis of user behavior in www search. Poster Session presented at the Conference on Research and Development in Information Retrieval (SIGIR).

[19] Eyetools, Inc. (2007). Retrieved July 9, 2007 from http://www.eyetools.com/ inpage/research_google_eyetracking_heatmap.htm.

[20] Martin Månsson (2017). Patterns and predictability of visual attention in different street types, Master's Thesis in Spatial Planning, $30 \mathrm{hp}$ Blekinge Institute of Technology.

[21] Duchowski, A. (2007). Eye tracking methodology: Theory and practice. ( $2^{\text {nd }}$ ed.) Springer-Verlag, London

[22] Wedel, M. \& Pieters, R. (2006). Eye tracking for visual marketing. Foundations and Trends in Marketing: 1, No. 4, pp 231320.doi:10.1561/1700000011

[23] Martin Månsson (2017). Patterns and predictability of visual attention in different street types,Master's Thesis in Spatial Planning, $30 \mathrm{hp} \mathrm{Blekinge} \mathrm{Institute} \mathrm{of} \mathrm{Technology}$

المرجع السابق [24] [25]

[25] [المرجع السابق

\section{Title Arabic:}

$$
\begin{aligned}
& \text { نحو إطار عمل لاراسة مؤشرات الانتباه البصري في بيئة تصميم } \\
& \text { الشوارع باستخدام جهاز تتبع العين الاتباه الثري }
\end{aligned}
$$

\section{Arabic Abstract:}

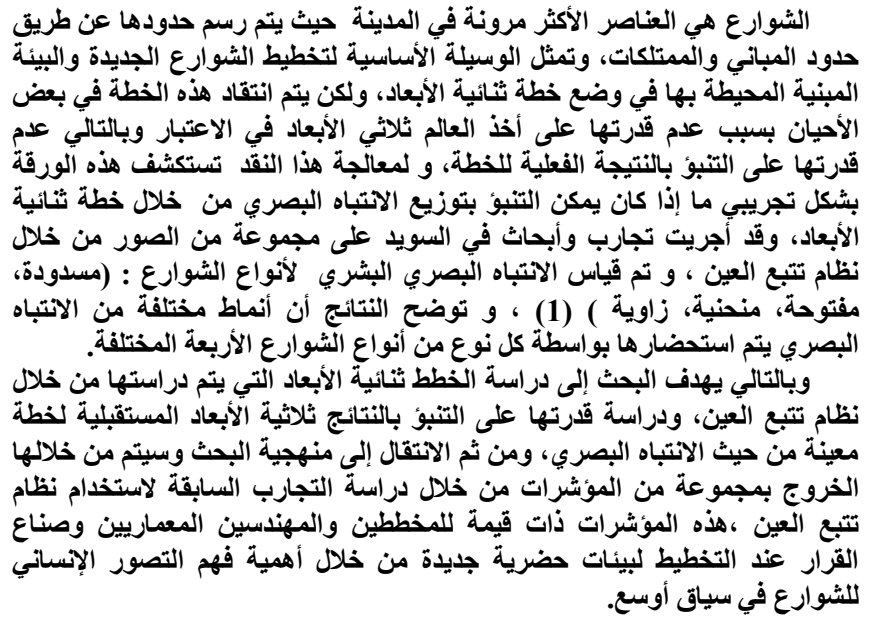

\section{-VII}

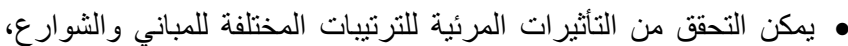

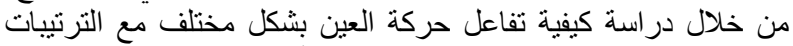

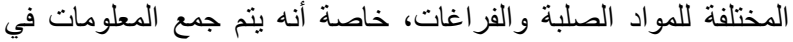

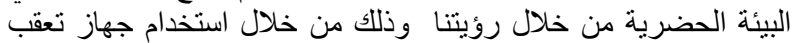

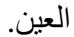

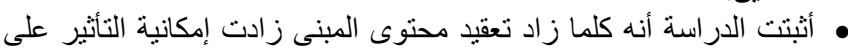

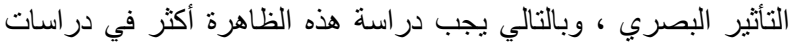
تتبع العين المستقبلية. • أثتبت الدراسة أن نوع الثارع هو أكبر محدد لكيفية توزيع الانتباه البصري

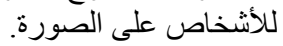

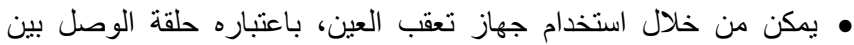
المستخدم و الفراغ ، الحفاظ على القيم الجمالية و الفنية للشو ارع عاره الحضرية.

\section{VIII}

• تحديد أنماط الرؤية الفسيولوجية الآلية المستخدمة لتحديد الترتيبات المكانية

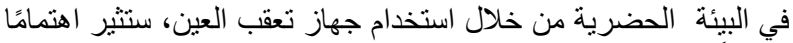

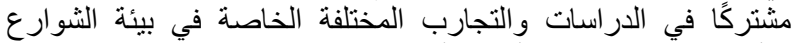

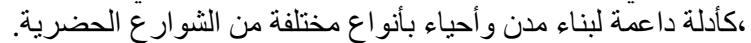

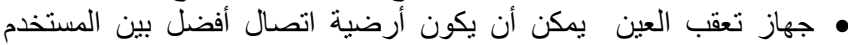

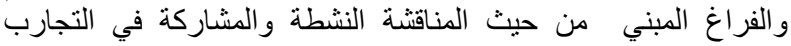
و الار اسات اللاحقة.

• يمكن من خلال تحليل مؤشر ات إطار العمل العمل المقترح في العملية التصميمية الوصول إلى تصميم مثالي للشو الثن إن عار الحضرية.

$$
\text { المراجع }
$$

[1] Boverket. (2017). How Sweden is planned Retrieved on 2017-03-23. http://www.boverket.se/en/start-in-english/planning/ how-sweden-isplanned/

[2] Trancik, R. (1986). Finding lost space: theories of urban design Van Nostrand Reinhold Company, New York

[3] Brown, S.C., Perrino T. \& Szapocznik, J. (2007). Identifying Streetscape Features Significant to Well-being. University of Sydney. Architectural Science ReviewVolume 50.3, pp 234-245

[4] Marshall, Stephen. Streets and Patterns. Canada: Spon Press, 2005.

[5] Hawkes, Amber and Georgia Sheridan. "Rethinking the Street Space: Why Street Design Matters." Planetizen 23 July 2009

[6] Appleyard, D., Guerson, M. S., Lintell, M. (1976). Liveable urban streets: Managing auto traffic in neighborhoods. Government Printing Office, Washington DC

[7] Department for Transport. (2007). Manual for Streets.Thomas Telford Publishing, Londo.

[8] Robinson, J. B. (1899). Principles of architectural composition; an attempt to order and phrase ideas which have hitherto only been felt by the instinctive taste of designers. The architectural record co, New York

[9] Lawson, Bryan. (2001), "The Language of Space", 1st edition, architectural press, Oxford, p (13)

[10] Gunawardena, G. Kubota, Y. \& Fukahori, K. (2015). Visual complexity analysis using taxonomic diagrams of figures and backgrounds in japanese residential streetscapes.

[11] Arnheim, R. (1974). Art and visual perception: A psychology of the creative eye. University of California, Los Angeles.

[12] Downes, M., \& Lange, E. (2015). What you see is not always what you get: A qualitative, comparative analysis of ex ante visualizations with ex post photography of landscape and architectural project. Landscape and Urban Planning. 